In an analogous research carried out last year by me, ${ }^{2}$ by Quincke's method of capillary ascension, and measuring the displacement of the liquid column under the influence of the magnetic field by means of an arrangement including a photoelectric cell connected with a galvanometer through an amplifying audion circuit, I predicted the difficulty of separating the Bose effect from the thermal effect, both in the same sense, and the latter certainly stronger.

Experiment confirmed this prediction, since the change in susceptibility which I observed when the light of a mercury arc was concentrated on a solution of chromic sulphate, $a$ change which increased with the time, could not but be interpreted, as I interpreted it, as due to pure thermal effect.

I also succeeded, however, in bringing to light another fact: a very small increase of magnetic susceptibility of the solution, which manifested itself immediately the solution came under the influence of light, and rapidly disappeared, to give place to the variation of opposite sense due to thermal effect. Of this increase in susceptibility it is difficult to give a plausible explanation : given the characteristic of variability in the magnetic moment of the ions of the first transition series, a characteristic which is bound up with the presence in the solution of complex ions, the facts might perhaps point to some influence of light on the concentration of such ions.

Istituto Fisico A. Righi, O. SPECchia. Bologna.

1 C. J. Gorter, NATURE, 130, 60, July 9, 1932.

o. Specchis, Nuovo Cimento, 8, 291; 1931.

\section{Crystal Structure and Dehydration Figures of Alkali Halide Hydrates}

Mrasurements of the cell dimensions of sodium bromide and sodium iodide dihydrates have been made by means of Weissenberg and oscillation photographs about the crystallographic axes. The results are as follows :

$\mathrm{NaBr} .2 \mathrm{H}_{2} \mathrm{O}$. Monoclinic. $a=6 \cdot 59, b=10 \cdot 20$, $c=6.51$ A.u. $\beta=112 \cdot 5^{\circ} . a: b: c=0.646: 1: 0.638$. The probable error is about 0.5 per cent. The axial elements given by Groth ${ }^{1}$ are $a: b: c=0.6469$ : $1: 0 \cdot 6335, \beta=113^{\circ} 13^{\prime}$. The number of molecules per cell is 4 . The density calculated from these values is $2 \cdot 28$; in the literature ${ }^{2,3}$, the values given are $2 \cdot 34$ and $2 \cdot 165$ at $16 \cdot 8^{\circ} \mathrm{C}$. The halvings observed are ( $h 01)$ when $h$ is odd and $(0 k 0)$ when $k$ is odd. Hence, the space-group is $C_{2 h^{5}}-P 2_{1} / a$.

NaI. $2 \mathrm{H}_{2} \mathrm{O}$. Triclinic. $a=6 \cdot 85, b=5 \cdot 76, c=$ $7 \cdot 16$ A.u. $\alpha=98^{\circ}, \beta=119^{\circ}, \gamma=68 \frac{1}{2}^{\circ}$. Hence $a: b: c=1 \cdot 190: 1: 1-243$. The probable error is about 0.5 per cent. The number of molecules per cell is 2 and the space-group $C_{i}{ }^{1}-P \overline{\mathrm{r}}$. The density calculated from the above values is $2 \cdot 67$, whilst that given in the literature ${ }^{3}$ is 2.448 at $20.8^{\circ} \mathrm{C}$.

Both substances are deliquescent, and it is difficult to free the crystals from adhering mother liquor. This probably explains why the formula given by Favre and Valson ${ }^{3}$ was $\mathrm{NaI} 4 \mathrm{H}_{2} \mathrm{O}$. The X-ray measurements show that this formula is improbable, because the minimum volume oceupied by all the atoms in the unit cell would be 266 cubic A.u., whereas the actual volume is 230 cubic A.u. The density determination by these authors is also probably in error because of the same difficulty.

No. 3288, VoL. 130]
The structure of $\mathrm{NaCl}_{2} 2 \mathrm{H}_{2} \mathrm{O}$ has not yet been investigated because it decomposes rapidly at ordinary temperatures but work on it is in progress.

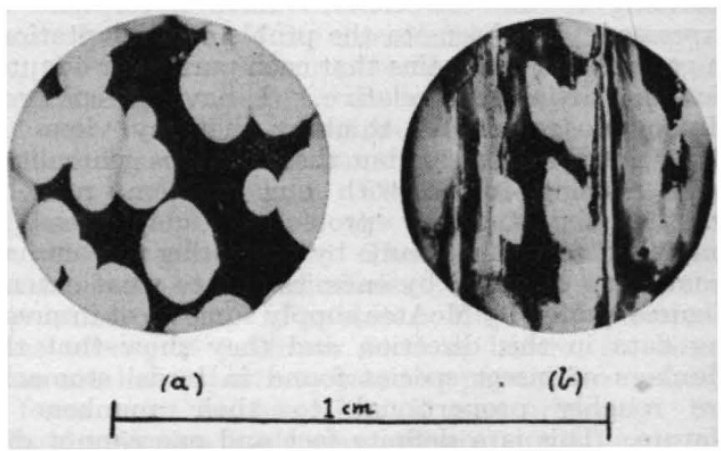

Fro. 1.-Dehydration figures of $(a) \mathrm{NaBr} .2 \mathrm{H}_{2} \mathrm{O}$ (20 hours over calcium chloride) and (b) $\mathrm{NaI} .2 \mathrm{H}_{2} \mathrm{O}$ (4 weeks over calcium chloride).

Both the hydrates show well developed dehydration figures when allowed to stand over calcium chloride for about twenty hours in the case of the bromide and for four weeks in the case of the iodide. The dehydration starts at points on the surface and spreads out forming very shallow white elliptical patches. Photographs are shown in Fig. 1. It is hoped that a full account of this work, together with the relation of the dehydration figures to the crystal structure, will 'shortly be published in the Zeitschrift für Kristallographie.

Department of Mineralogy and Petrology,

Cambridge,

Sept. 28.

1 Groth, "Chemische Krystallographie", vol 1, p. 234.

'Playfair and Joule, Mem. Chem Soc., '2, 401.

Favre and Valson, C.R., 77, 579 .

\section{Magnetic Constants of Benzene, Naphthalene and} Anthracene Molecules

Is a recent communication ${ }^{1}$, I have shown how, by a correlation of the principal susceptibilities of a diamagnetic erystal, with those of the constituent molecules, it is possible to determine the orientations of the molecules in the crystal. Conversely, where the orientations are already known from $\mathbf{X}$-ray measurements, we can calculate the molecular magnetic constants from those of the crystal. The principal susceptibilities of naphthalene and anthracene molecules, calculated in this manner, are given in the following table. Two of the magnetic axes of the molecules lie in the plane of the benzene rings, one along the line joining the centres of the rings and the other perpendicular to this line. The third axis is normal to the plane of the rings. The susceptibilities along these axes, per gram molecule, are denoted by $K_{1}, K_{2}$ and $K_{3}$ respectively. The values for the benzene molecule, which are also included in the table, have been calculated (in the

\begin{tabular}{|l|c|c|c|}
\hline \multicolumn{1}{|c|}{ Molecule } & $-K_{1} \times 10^{6}$ & $-K_{2} \times 10^{6}$ & $-K_{3} \times 10^{6}$ \\
\hline Benzene & 37.3 & $37 \cdot 3$ & $91 \cdot 2$ \\
Naphthalene & 39.4 & $43 \cdot 0$ & 187.2 \\
Anthracene & 45.9 & $52 \cdot 7$ & 272.5 \\
\hline
\end{tabular}

absence of magnetic data for the crystal) from 